\title{
El código digital. \\ Del estatuto de la arquitectura contemporánea
}

\author{
The digital code. \\ About the statute of contemporary architecture
}

\author{
Angelique Trachana \\ Universidades Politécnica de Madrid y Camilo José Cela de Madrid \\ 9737trachana@coam.es
}

Recibido: 7 de agosto 2011

Aprobado: 12 de febrero 2012

\begin{abstract}
Resumen
En este trabajo se pretende estudiar las relaciones e influencias que se establecen entre la concepción de la arquitectura contemporánea y las tecnologías de la información y la comunicación señalando las profundas transformaciones producidas por estas. El método para llevar a cabo esta investigación rastrea la evolución de las teorías estéticas desde la modernidad verificando un proceso que desemboca en la estética de los objetos virtuales. En este proceso se comprueba -en clave crítica- la relación entre las más significativas tendencias de la arquitectura a partir de los sesenta con una teoría de la comunicación basada en parámetros puro-visuales. El código digital es un código visual absoluto por lo que el proceso proyectual completamente producido por ordenador se somete a una revisión reivindicando la experiencia corporal de la arquitectura. Se vislumbra, no obstante, alguna posibilidad de optimizar las nuevas tecnologías en la configuración de espacios más humanos y mejor habitables.
\end{abstract}

Palabras clave: espacio arquitectónico, visual, virtual, corporal

Trachana, A. (2013): El código digital. Del estatuto de la arquitectura contemporánea. Arte, Individuo y Sociedad, 25(1) 43-64

\begin{abstract}
This paper aims to study the relationships and influences that exist between the conception of contemporary architecture and communication and information technologies pointing out its profound changes brought by that. The method to conduct this research traces the evolution of modern aesthetic theories verifying a process that leads to the aesthetics of virtual objects. In this process, is found, in critical key, the relationship between the most significant trends in architecture from the sixties with a theory of communication based on pure-visual parameters. The digital code is an absolute visual code and so the project processes completely produced by computer is submited to a review claiming bodily experience of architecture. One sees, however, a possibility to optimize new technologies in shaping human spaces and better living.
\end{abstract}

Key Words: architectural space, visual, virtual, corporal

Trachana, A. (2013): The digital code About the statute of contemporary architecture. Arte, Individuo y Sociedad, 25(1) 43-64 
Sumario: 1. Aura y tecnología, 2. Del espacio abstracto-visual al espacio virtual, 3. Hacía la estética informacional, 4. Tecnología y comunicación, 5. Experiencia del cuerpo y código digital, 6. Arquitectura y cuerpo ampliado por la tecnología, Referencias

\section{Aura y tecnología}

Asistimos hoy a un proceso expansivo del entorno virtual consecuencia de las tecnologías de la información y la comunicación (TIC) que implica un profundo cambio de la percepción del espacio-tiempo. Un "principio de desrealización" o erosión de la realidad, se dice, está transformando las conciencias y, si [sí] es verdad, influye directamente el proyecto arquitectónico: la configuración del espacio vivencial. Las TIC condicionan los procesos proyectuales y la semántica de la arquitectura. El objeto arquitectónico se concibe como imagen y se dota principalmente de propiedades adecuadas para su reproducción y difusión. El paradigma arquitectónico contemporáneo no es que niegue el 'aura', pero sí la adultera mediante estrategias que pertenecen al mercado de la información más que en el propio estatuto del arte; estrategias promovidas por diferentes instituciones y a través de la valoración económica hiperbólica de la firma de algunos autores (Perniola, 2002, p.78).

El régimen plenamente secularizado y desencantado inaugurado por la reproducción técnica de la obra, confiere a la misma, según Benjamin (1936), un valor meramente expositivo pero inaugura, por otro lado, podemos decir, una relación de proximidad con el público mientras que el régimen tradicional de la obra caracterizado por el 'aura', es decir, por el valor cultural atribuido a un objeto único y duradero, requería una experiencia estética fundada en una relación de distancia con respecto al que la disfruta.Si se considera la vicisitud de la arquitectura de los años 60 en adelante, parece que aquella -como las artes plásticas- siguió un camino bastante diferente al marcado por Benjamin; en efecto, éste relaciona la desaparición del 'aura' con la disolución del criterio de autenticidad de la obra y con la transformación del autor en una especie de operador técnico. Ahora bien, los tres elementos, del arte -aura, obra, autor- han sufrido transformaciones inesperadas. En lo que respecta a la permanencia en la expresión del arte de una dimensión trascedente -no distinta de la religiosa-, se puede poner en duda que la secularización se haya producido efectivamente. "El paradigma religioso articulado sobre las tres figuras del profeta, de los fieles y del cura" (Bourdieu, 1971), sería pertinente para explicar el paradigma arquitectónico articulado sobre las respectivas figuras del artista, del público y el especialista o intérprete. El autor se implica en un proceso de singularización sin precedentes, que ha infligido el principio de universalidad sobre los que se fundaba la experiencia estética moderna -desde el siglo XVIII en adelante-. La singularidad y sus manifestaciones más transgresoras han acabado constituyendo el principal criterio de valor de la arquitectura actual. En cuanto al principio de autenticidad benjaminiana de la obra, sin duda se ha reforzado extraordinariamente dado que procedimientos desde el ready made o objet trouve hasta el montaje, el collage y el 'ars combinatoria' de la computadora -delimitada por la programación- se han dotado de autoridad cultural y pueden ser garantes del valor de la obra (Perniola 2002, p.73). 

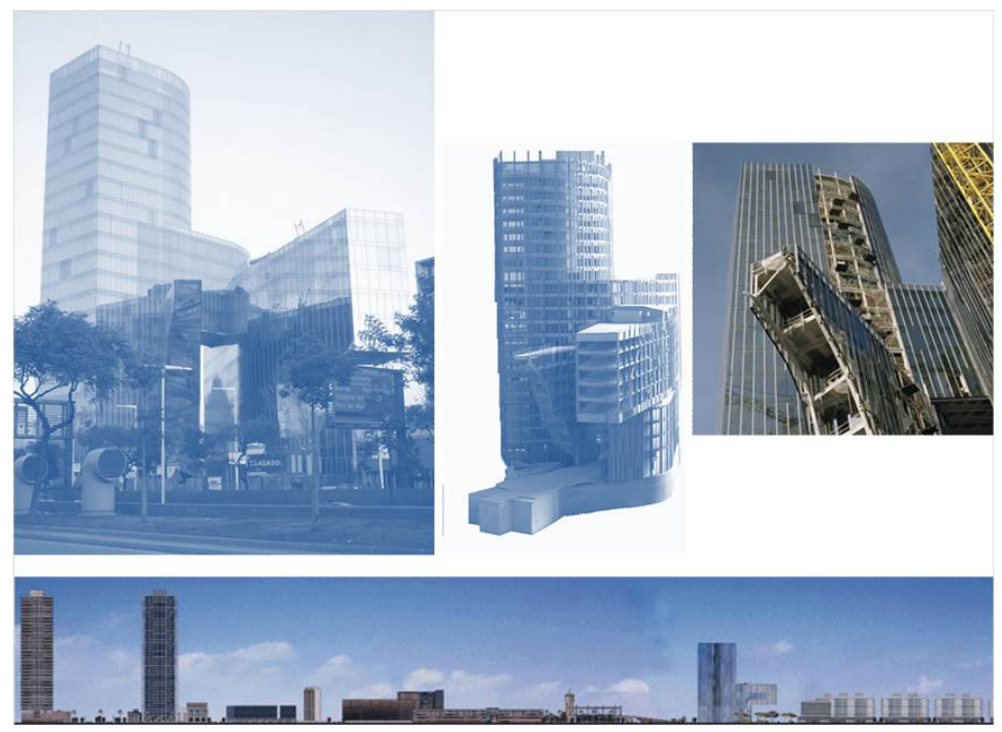

Fig. 1. Nueva Sede de Gas Natural, Barcelona, de EMBT: Miralles-Tagliabue y Julio Martínez Calzón (ingeniero). Un impresionante voladizo de treinta metros emerge entre las plantas cinco y nueve, una auténtica proeza ingenieril para provocar un interesante efecto visual entre la verticalidad y la horizontalidad, entre la estabilidad y la inestabilidad.

La imagen singular constituye el eje de la investigación arquitectónica (véase como ejemplo fig.1), superando con creces los esfuerzos destinados a otras dimensiones de la arquitectura relegadas habitualmente a las diferentes ingenierías, lo que tiene como consecuencia la sectorialización de su proceso productivo, su total dependencia de las diferentes tecnologías y su separación de otras problemáticas urbanas y sociales. Eso queda demostrado en el material gráfico y fotográfico que nutre las publicaciones específicas, de un alto grado de abstracción, indeterminación y descontextualización. La imagen digital tiene un enorme atractivo per se y como tal se articula difícilmente con el realismo de un lugar concreto, con los materiales concretos de la construcción o con las circunstancias reales personales o de grupos de personas. El medio donde más cómoda se encuentra la arquitectura hoy es, sin duda, el medio infográfico, un medio abstracto, geométrico, mejor dicho, numérico, un medio sin conflictos sociales y ambientales, sin valores históricos, culturales y geográficos. Donde la arquitectura tiene más éxito es en las revistas y aun mayor en las pantallas. No es casual que los certámenes más importantes, Bienales y otras exposiciones de arquitectura, se realicen últimamente con proyecciones y los planos son cada vez menos específicos, se parecen más a imágenes tridimensionales. Las imágenes, además, no siempre sirven de patrón para llevarse a cabo la construcción, no siempre el objetivo del proyecto es su construcción. Muchas veces, el cometido principal de la arquitectura -si es "el arte de construir"- no se implementa racionalmente sino muy costosamente con la construcción, lo que hace el 'diseño' innovador incompatible con la sostenibilidad, con criterios ambientales y las condiciones culturales del lugar. La traducción de una imagen digital singular en estructura y elementos constructivos, se convierte así, tantas veces, en un juego audaz, alarde de ciencia y opulencia. 


\section{Del espacio abstracto-visual al espacio virtual}

La investigación sobre el espacio arquitectónico que ocupó las vanguardias arquitectónicas del siglo XX iniciada en las indagaciones teóricas de Auguste Schmarzow, Alois Riegl, Lászlo Moholy-Nagy, Van Doesbourg Rietveld y que prosiguió con los experimentos de los formalistas rusos, los Prounen de El Lisitzky, los Merzbau de Kurt Schwitters, el neoplasticismo, los prototipos de Mies van der Rohe, Le Corbusier y tantos otros hasta encontrarnos con Guggenheim, se ha fundado sobre la pura visualidad y la abstracción como verdadero estimulante de la percepción (Jameson, 1996, pp. 147-148). Como observaba Benjamin, el arte moderno, en el conjunto de sus expresiones, tenía una vocación de potenciar la experiencia visual. Este fue el objeto también de la arquitectura moderna más allá de sus postulados funcionalistas y organicistas. Superando el determinismo biotécnico así como la confianza al modelo taylorista, las líneas proyectuales han ido apuntando hacia una estetización de la tecnología. La iconografía del high-tech facilitada por la imagen digital, el uso no convencional de materiales que denotan singularidad y exclusividad, la conversión del edificio en contenedor de diversas tecnologías y equipamientos técnicos - redes, computadoras, domótica, robótica,- y la concepción del espacio como espacio expositivo -el espacio del museo como el más característico paradigma contemporáneo-, se convierten en los auténticos detonantes de innovación espacial (véase en fig. 2 dos tempranos ejemplos de arquitectura high-tech).

La tecnología es, a veces, justificada con argumentos ecohumanistas, la mayoría de las veces, retóricos y vacíos de contenido (fig.3).

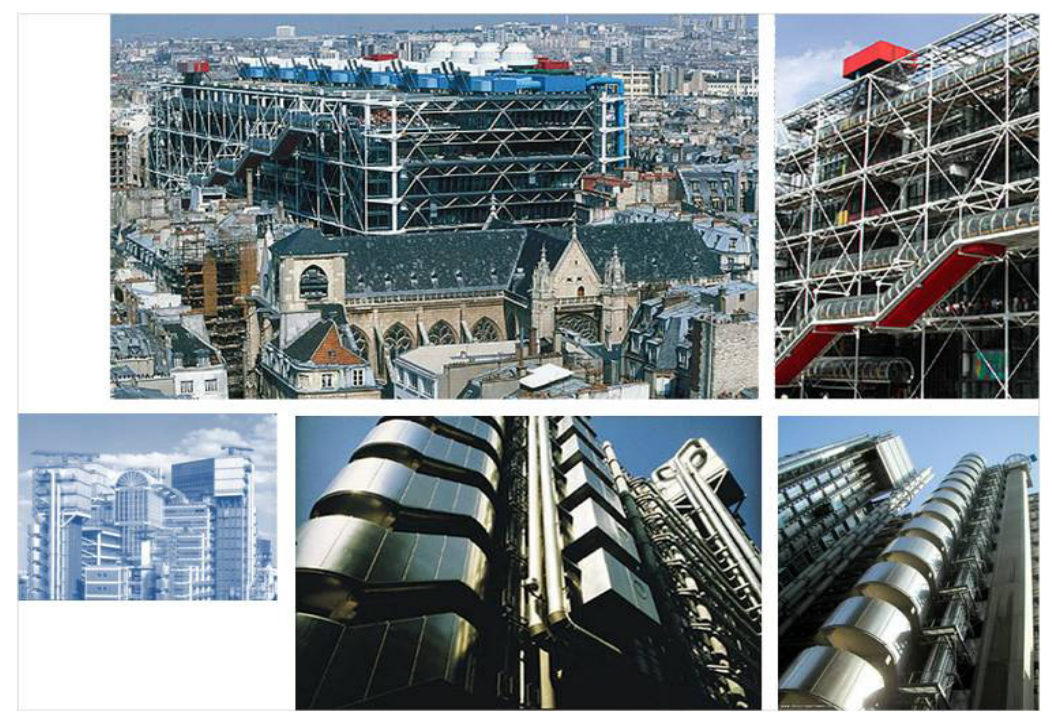

Fig. 2. Arriba: El parisino Centro Pompidou de Rogers y Piano (1977). Abajo: El edificio londinense Lloyd's de Rogers (1984). Aparecen como simulacros -pseudosoluciones de pseudoproblemas formulados en el proyecto en torno a diversos expertos tecnológicos muy cualificados-, cuando se trataba de garantizar una anticonvencionalidad de la obra para satisfacer una necesidad de comunicación. 
Podríamos decir, por tanto, que más allá del aura y de la reproductibilidad técnica, la técnica constituye una de las dinámicas más vivas de la arquitectura contemporánea y se convierte en la imaginación tecnológica, como una forma de animación de lo no vivo. Eso quiere decir, que no es tecnológica en el sentido funcional del término como tampoco es religiosa en el sentido tradicional aunque participa de ciertas patologías de la experiencia religiosa. Eso es la forma del fetichismo o de la funcionalidad respecto a las exigencias de una sociedad que ya no tiene necesidad de mantener la autonomía relativa de las actividades simbólicas, pues, las actividades simbólicas a través de la dismitificación y el 'desenmascaramiento' (Vatimo, 2003) tienden a transformarse en funciones del sistema productivo sumidas en una relación de referencia inmediata a las exigencias de la producción y de la organización social; una dependencia directa de los imperativos económicos.

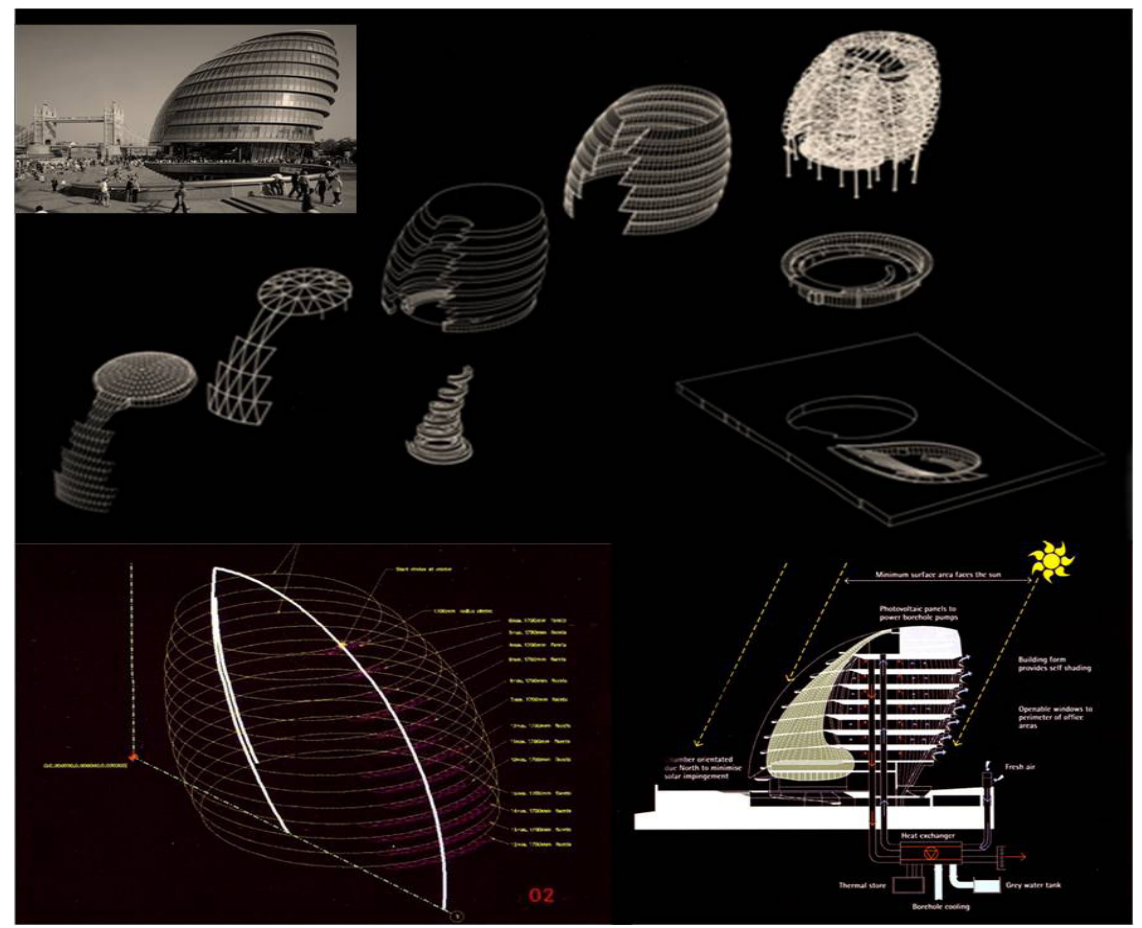

Fig. 3. Ayuntamiento de Londres (2002) de Foster and Partners. La forma parece dada por estudios bioclimáticos y que cada pieza de la piel del edificio está calculada y fabricada para responder con precisión a las condiciones puntuales.

El ciberespacio es el espacio donde se realizan la mayoría de las facetas de la vida, de las relaciones humanas, del trabajo, la cultura y el ocio suplantando cada vez más los escenarios reales de la vida cotidiana y simbólicos del hombre. La arquitectura como imagen simbólica efectivamente pierde su protagonismo frente a los massmedia. Al libro impreso -que superó la arquitectura en cuanto medio de transmisión de significados, según lo anunciado por Victor Hugo en aquel lúcido texto, "Esto matará aquello" (Nuestra señora de París, libro V, capítulo 2), sucedieron 
la fotografía, el cine, la tele-visión y luego las redes imponiendo nuevos patrones de percepción del espacio y de comunicación. Nadie hubiese imaginado la enorme repercusión en el campo arquitectónico de los massmedia y definitivamente de las redes de comunicación. Aquella afirmación macluhaniana "el medio es el mensaje" (McLuhan, Fiore, 1967) tiene inmediata verificación. Los medios, efectivamente, son un componente constitutivo del acto enunciativo, son parte ya integral de la obra, son la obra y son constituyentes de una nueva "cultura estética", de nuevos patrones de percepción. Estamos ya inmersos en un tercer entono técnico-medial, como diría el filósofo Javier Echeverría (1994), -el primero, de los tres sucesivos entornos vitales del hombre fue la naturaleza y el segundo, el medio urbano-, dominio intangible de "Los señores del aire" (Echeverría, 1995). De la ciudad, teatro de las actividades humanas, con su ágora, su plaza de mercado poblada de actores y espectadores presentes, a la cinecittà o telecittà poblada de telespectadores ausentes, sólo había que dar un paso. Desde la lejana intervención de la ventana urbana, el escaparate, ese poner los objetos y las personas dentro de un cristal -transparencia aumentada en el curso de los últimos decenios-, habría de llegar, más allá, a la óptica fotocinematográfica y de esta a la óptica electrónica. Los nuevos medios técnicos serían capaces de realizar, además de inmuebles-escaparate, ciudades y naciones-escaparate, megalópolis mediáticas que poseen el poder paradójico de reunir a distancia los individuos, en torno a unos determinados modelos de opinión y de comportamiento (Virilio, 1998, p.21).

Según Mario Perniola (2002), esa tendencia actual que nos lleva hacia la separación, alejamiento y suspensión de la realidad tiene efectivamente como potente aliado los medios de comunicación de masas: la idea del espectáculo de masas, la poética de lo efímero y la comercialización del tiempo libre que han favorecido el aspecto hedonista y lúdico de la arquitectura. Pero la noción de lo virtual que, a primera vista, parece aportar elementos a favor de la desrealización y del alejamiento de lo real, ha abierto una nueva problemática. Lo real que irrumpe y sacude el mundo del arte, no es sólo aquello arraigado en la dimensión antropológica, sino también y, sobre todo, aquello más bien ajeno e inquietante de los dispositivos tecnológicos y económicos. El lugar decisivo de este realismo extremo se convierte, así, en el encuentro entre el ser humano y la máquina, entre lo orgánico y lo inorgánico, entre lo natural y lo artificial, entre la pulsión y la electrónica, entre la persona y la mercancía. El núcleo duro de lo real con el que estamos obligados a enfrentarnos es el cyborg, la cobaya tecnológica, la moneda viva, el capital humano.

La noción de virtual, que a primera vista nos parecía unida a la tendencia espectacular y desrealizante del espacio-tiempo, asume un significado opuesto: el cuerpo virtual, poseído y diseminado en las redes, se convierte en otro objeto, extremadamente inquietante, irreducible a la dimensión imaginaria y simbólica. Aparece así la idea del observador o el habitante incorpóreo que se desprende de una relación corpórea con el entorno a través de la supresión del resto de sentidos y en concreto mediante las extensiones tecnológicas del ojo. "La realidad ha llegado a parecer cada vez más a lo que muestra la cámara" (Sostang, 1973), una escenografía vaciada de la autenticidad de la materia y de la construcción. La fotografía había sido anticipada por la pintura que se transformó en precursor de la cultura de masas cuando se volvió hacia al gran público, mucho antes incluso que la instantaneidad 
visual de las obras de los impresionistas, o el cubismo que han considerado la visión inmediata como un fin en sí mismo. "La utopía histórica del Arte desde los griegos al Renacimiento y la dinastía Tang fue la renovación de la percepción visual hasta llegar en ese entorno del puro simulacro" (Virilio, 1998, p. 25). Las nuevas tecnologías como extensiones de los sentidos hasta ahora han reforzado aun más la primacía de la vista, debilitando y las experiencias del cuerpo y convirtiendo el mundo en un viaje visual y virtual hedonista. La experiencia del espacio y del tiempo se ha fundido en una única mediante el incremento de la velocidad en el mundo tecnológico, lo que produce como consecuencia una vuelta a las dos dimensiones (Harvey, 1990, p.293), lo que corresponde a la visión lejana. El acercamiento antropológico, nuestra relación física y háptica con el espacio ofrece, sin embargo, datos esclarecedores de la importancia de los aspectos intuitivos e inconscientes en el uso del espacio y en la comunicación conductual como base proyectual de espacios íntimos y bioculturalmente funcionales mientras que la visión distancia, separa y posibilita una postura nihilista. Pero los arquitectos, ingenieros, diseñadores igual que los artistas plásticos y músicos utilizan el espacio virtual o ciberespacio para proyectar y crear en el ordenador (Montaner, 1999 pp. 106-108).

\section{Hacia la estética informacional}

El racionalismo, hay que recordar, se convirtió en un lenguaje expresivo como se hizo explícito en el "less is more" de Mies van der Rohe. Eso que resultaría hasta cierto punto tranquilizador para Max Weber (1970, pp. 79-105) a quien preocupaba la tendencia a la racionalización de todos los aspectos de la vida moderna, lo que hacía era separar la arquitectura de las otras esferas de la vida a favor de un código visual reduccionista. Desde el concepto idealista de Hegel sobre el arte como "la apariencia sensible de la idea", o el concepto heideggeriano del arte como revelación y aletheia, se recondujo la atención arquitectónica por la teoría de la 'pura visibilidad' a los valores formales tales como se nos ofrecen a la visión como objeto autónomo, dejando atrás la representación y la significación. El formalismo moderno se ha basado para sus análisis en la Gestaltpsycologie y, sobre todo, en la ley del isomorfismo, según la cual se preestablecía automáticamente una especie de armonía natural entre los esquemas mentales y el universo físico que era la base de la objetividad que justificaba la obra. K. Fiedler (1887) concebía la forma artística como una manera peculiar en que nuestra actividad espiritual recoge y filtra los datos caóticos que nos proporciona la experiencia visual.

La estética de las vanguardias que atravesaba el constructivismo, el futurismo, el neoplasticismo... como herencia del formalismo decimonónico se basó así en la teoría de la pura visibilidad que se prolongó hasta los años sesenta en un arte sintáctico y a la imagen tenco-industrial. A partir de los 60, las vanguardias estrecharon los lazos de la Estética con la teoría del estructuralismo y la lingüística proporcionándonos otra teoría estética reducida a una teoría de los signos. Y a partir de los ochenta, siguiendo todavía, al parecer, el proceder metodológico kantiano nunca abandonado en la búsqueda de universalidad y objetividad de condiciones a cumplir por la obra, se establecían unos principios a posteriori o extraídos de la observación de la 
obra. La hermenéutica de la obra se ha basado prioritariamente en metáforas de las ciencias exactas que daban lugar a neoformalismos abstractos como expresiones más conocidas del arte y de la arquitectura, encaminadas decididamente hacia la carrera informática de los procesos generativos de la forma y la imagen digital. Pues, la última revolución técnica tendría consecuencias análogas de la revolución industrial. Si podemos hablar de una estética industrial, igualmente podríamos hablar de una estética de la información y una nueva modelización de la visión. El alemán Max Bense (1973) y el francés Abraham Moles (1976) podrían considerarse los dos principales teóricos fundacionales de la Estética Informacional. El pensamiento estético de Bense está vinculado a la teoría de la ciencia y se concibe dentro de las sociedades altamente desarrolladas tanto industrial como tecnológicamente. El conjunto de sus escritos constituyen un intento para crear una estética científica y una aportación más completa, a pesar de sus limitaciones y falta de conclusión, a la estética cibernética. Bense considera la estética una 'disciplina filosófica aplicada' centrando su interés por las matemáticas y su preocupación en torno a la aproximación del arte y la ciencia, en un interés más genérico por el mundo de los signos y la semiótica así como el interés por las filosofías neopositivistas del lenguaje (Marchan Fiz, 1973, pp.7-17). Abraham Moles empieza a desarrollar su Teoría de la información y percepción estética en 1958 y se presenta como defensor del Arte tecnológico en su dimensión cibernética.

El arte -en términos generales, la formatividad- del futuro estaría basado en las máquinas, capaces de manipular la complejidad, ofreciendo de esta manera posibilidades insospechadas para abrir nuevos caminos a la expresión del ser humano como herramientas capaces de realizar todo aquello que se propusiese su imaginación en un intento de aproximación progresivo de éstas al arte a partir de su gran capacidad creativa fomentada en las posibilidades que ofrecían para combinar los diferentes elementos. Moles introduce el concepto de 'simulacro' entendido no sólo como simple copia de un original, sino como una versión siempre nueva basada en el 'grado de operatividad' que pudiera lograrse. El valor del simulacro implicaría el abandono del criterio tradicional de verdad en estética por el de 'operatividad' de carácter tecnológico como también señala Lyotard (1979, p.11): "el criterio de operatividad es tecnológico, no es pertinente para juzgar lo verdadero y lo justo". Las máquinas pueden simular la creación intelectual y por lo tanto la primordial correspondencia a la simulación de objetos artísticos, para lo cual se haría necesaria la existencia de programas frente a los que el artista debe comportarse como esteta, estableciendo criterios artísticos, y como programador al mismo tiempo, en la búsqueda de los algoritmos necesarios que expresan tales criterios.

Así en la actividad creadora -el arte cibernético-, la máquina puede ser más que una herramienta o instrumento de trabajo que resulta de gran ayuda, dada una potente memoria y rapidez para procesar datos desarrollando una idea de composición prevista en el programa. La máquina asume un papel activo ofreciendo combinaciones imprevisibles, posibilidades insospechadas para el autor, opera como un creador adicional y como introductor de criterios estéticos que sustituyen las tradicionales reglas de la composición, armonía, etc. (S. Marchán, 1986.3, p.386). 


\section{Tecnología y comunicación}

Si es verdad que, desde el neopositivismo del Círculo de Viena (1922-38) al minimalismo, en torno a los 60, dominaba una matematización de la estética debida a una visión científica del mundo, por otro lado, hacia mediados de los años sesenta, se sentenciaba el agotamiento del neopositivismo estético, y se ponía en crisis la arquitectura industrial y el urbanismo del zonning. Dentro del fervor del mayo francés, se cuestionaban los modelos sociales y económicos que los sustentaban. La teoría estética se abría como una crítica del formalismo mecanicista y permitía un trasvase, casi literal, al campo estético de los modelos lingüísticos. Pero, partiendo de la base lingüística se trasgredía la codificación lingüística en todo el elenco posestructuralista de los posmodernismos y 'deconstructivismos'. Uberto Eco (1997), uno de los portavoces de la semiótica, reconocía que el rasgo más sobresaliente de la obra artística era el hecho de que no se daba una relación unívoca entre la obra y sus contenidos. El arte se consideraba un proceso no estructurado e imprevisible, de interacción comunicativa con el espectador que escoge y activa sus lecturas e interpretaciones, abocada, por tanto, a la hermenéutica. En la estética hermenéutica de H. Gadamer (1998) y P. Ricoeur (1995) adquieren carácter primordial el creador y el espectador como productor y activador de sentido. Y la estética de la recepción heredera de "la crítica del lenguaje" de principios del siglo, abandonaba la formalización del sentido de la obra para reconstruir la polifonía instintiva de la "forma abierta". Asistimos así a una disolución de la estética en una teoría general de los signos y a técnicas de la interpretación vinculadas al psicoanálisis.

Jacques Derrida encontró en la arquitectura un recipiente para el trasvase de la deconstrucción literaria. Según Derrida (1989), la vida psíquica y la vivencia estética, no son una transparencia de sentido, ni una opacidad de fuerzas, sino la différence en el trabajo de esas fuerzas. La afirmación gozosa sobre un mundo de signos sin centro ni jerarquías, sino abierto a la interpretación activa, se decantaba hacia la "diseminación", figura que inspira a toda una corriente de la cultura francesa preocupada por el estudio del lenguaje poético y las posiciones del lenguaje artístico emparentadas con la "filosofía del deseo", como el "ezquizoanálisis" de G. Deleuze y F. Guattari, o las posiciones de J. F. Lyotard (1979). El 'esquizoanálisis' no se estructura, sino que se 'rizomatiza', es decir, se conecta con múltiples líneas y se abre como un campo de saber que es a la vez ciencia y también arte, política y también filosofía. Los autores proponen una nueva versión del inconsciente, un inconsciente productivo y creacionista, en lugar de un inconsciente representativo, reducido a lo familiar. El 'esquizoanálisis' es una forma de pensar, una manera de vivir, una modalidad de análisis permanente, que busca introducir el deseo en la producción y la producción en el deseo. $\mathrm{El}$ arte es fuente fundamental de esas potencias que busca vitalizar este pensamiento en cada persona. Según Lyotard, uno de los problemas claves de la posmodernidad, es la 'invalidez' de reglas de reconocer verdades absolutas e incontrovertibles, determinada por la performatividad del saber y sus reglas de juego que Lyotard llama la 'legitimidad pragmática' del saber, sea científico o narrativo. En todo caso, se buscaba el reencuentro de lo estético con lo lúdico y el juego que encontraba en las posibilidades combinatorias, del medio digital su mejor aliado. Moles (1976) descubre el 
arte permutacional -del signo sin significado- y propone una resignificación del ser artístico totalmente abstracto.

Ahora la creatividad ejercida como concepción de signos comunicativos, da lugar a que la creación y la recepción estéticas sean valoradas de forma inversamente proporcional al grado de automatismo asociado a ellos. El parámetro información es clave en los procesos formativos y para la estructuración del concepto estético. El proceso estético se constituye en un proceso comunicativo de información estética diferente de la información semántica (Bense, 1973) ya que su principal objetivo no es transmitir significado -de este modo se convertiría en un sistema cerrado basado en la transmisión unidireccional de información-. Esta tendencia -fuertemente objetivista, por otro lado- reduciría la comunicación aunque la participación del espectador y la interacción con la obra adquiriría, cada vez, mayor importancia en la concepción estética y el arte cibernético presupone una ampliación de la percepción y una ampliación de la comunicación. La "estética cibernética" -que debe su denominación a Herman Schmidt y a Helmar Frank y Herbert W. Franke-, pretende constituir el origen de una corriente antropológica y humanista de la Cibernética que profundice en la síntesis entre la teoría de la información, la teoría de la percepción, la neurología y la psicología de la información (Castillo, 2007). Sus procesos sintonizan con los procesos performativos del arte y las especies híbridas de la arquitectura -ecléctica, heterodoxa, paradójica, extrañante-. Esa última ya no guardaría fidelidad alguna a teorías, ni fenomenológica, ni semiótica, ni marxiana, ni hegeliana, ni freudiana..., pero sí seleccionaría aspectos teóricos de ellas.

De la estética tecnológica -que en los 70 y 80 nos proporcionó ciertas especies arquitectónicas- a la estética cibernética sólo habría de dar un paso. Edificios como el parisino Centro Pompidou de Rogers y Piano o el londinense Lloyd's de Rogers aparecieron como simulacros -pseudosoluciones de pseudoproblemas formulados en el proyecto en torno a diversos expertos tecnológicos muy cualificados-, cuando se trataba de garantizar una anticonvencionalidad de la obra para satisfacer una necesidad de comunicación. De allí a ejemplos más contemporáneos como los que encontramos en la arquitectura de Jean Nouvel (fig.4), la cuestión más importante para resolver era cómo intensificar la percepción sensorial y la seducción, asociando siempre tecnología y comunicación. Nouvel concentra su interés en el diseño de envolventes, traduciendo en ellas un interés por los envases o envoltorios de los productos de consumo. 

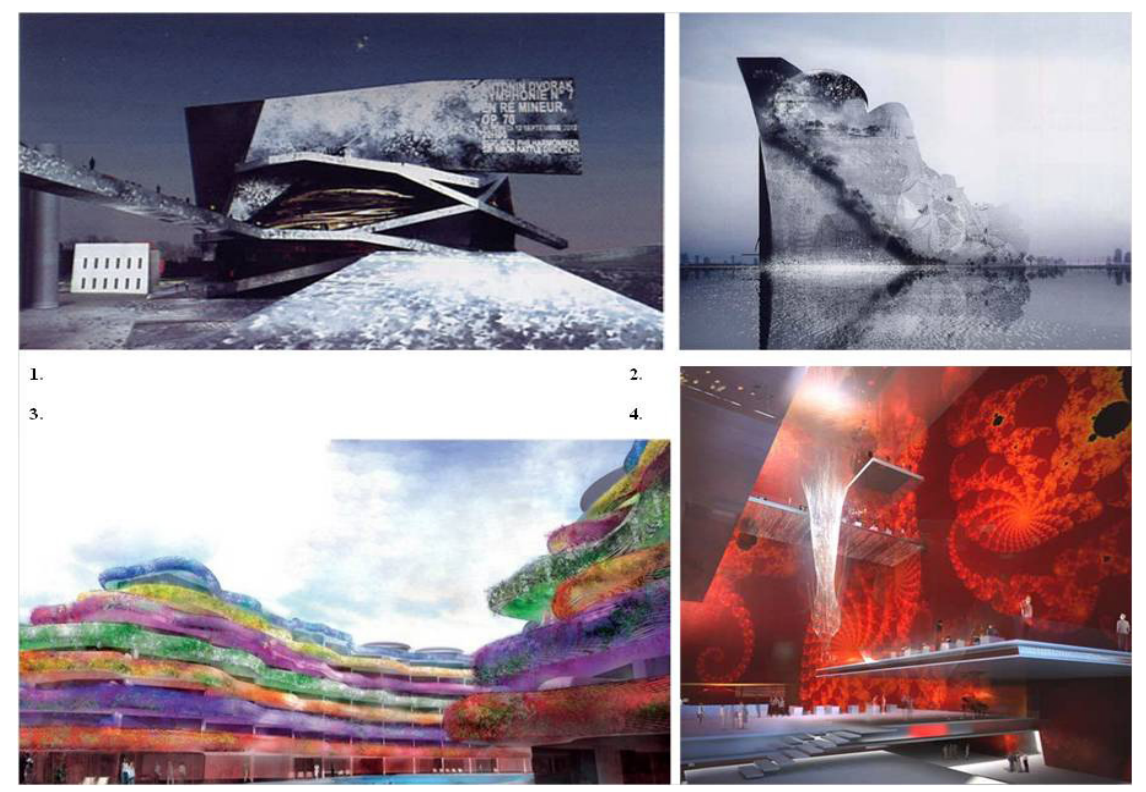

Fig.4. Jean Nouvel, concentra su interés en el diseño de envolventes, traduciendo en ellas un interés por los envases o envoltorios de los productos de consumo. 1. Filarmónica de París (2007). 2. Teatro de la

Opera de Dubai (2007). 3. Life Marina, Ibiza (2007). 4. Tour Signal, La Défense, Paris (2008).

"El medio es el mensaje" macluhaniano se traducía así, en un arte que ya no pretendía controlar y regular la autonomía de discurso y soporte. Según la lógica comunicacional, la arquitectura asumía la condición de disolverse como medio, soporte, forma o estructura, para reinstituirse en información, según el axioma de que fuera de la información no queda nada. Frente a la omnipresencia tecnológica y la teoría macluhaniana de la información como elemento redefinidor de todo soporte, el pensamiento hermenéutico se proponía, por otro lado, un trabajo decodificador de los infinitos contenidos de cualquier texto o soporte tratando de establecer los límites expresivos del lenguaje arquitectónico. Pero inversamente al optimismo macluhiano, arrojaba sus sombras un pesimismo que -derivando de la filosofía del lenguaje de Wittgenstein- comprobaba cómo el lenguaje ya no creaba comunicación. A más información tecnológicamente soportada parecía corresponder menos comunicación; un desgaste de la función intersubjetiva de los lenguajes. La palabra poética se redefine por Derrida y por Gadamer, como lo que queda, un 'sedimento de sentido incierto' (Gadamer, 1993, pp.107-117). Asumiendo la fragmentariedad y la fruición de todo discurso formal de la arquitectura se desplegaban dos principales alternativas: o el ruido ensordecedor de un discurso neo o hiperbarroco saturado y redundante, o el silencio minimalista orientado a operar con vestigios elementales de impresión, niveles mínimos de requerimiento de atención y la necesidad del trabajo interpretativo en el cual residía el goce. Quedaba así tensada la lógica comunicacional de la arquitectura entre el ruido mediático y el silencio comunicativo. 
Asumida la realidad de la hipercomunicación como un retroceso y una limitación de la comunicación, surgía la necesidad de confrontar de un modo distinto el proyectar y se ponía el acento en la ironía y la acidez -ante el desconcierto y la dificultad de descodificación del texto-proyecto-, que desvelaba el "pensamiento negativo" que va del "después" hegeliano con Nietzsche, Freud, Wittgenstein y Foucault. Este filón se actualizaba en el campo proyectual por arquitectos como Rossi y la tendenza italiana que traducen este filón recuperando los conceptos históricos de tipo, monumento o contexto pero utilizados como imágenes activas en la recomposición del nuevo proyecto mientras que F. Rella, M. Cacciari y M. Tafuri apoyados en el "pensamiento negativo" recuperaban también para la interpretación arquitectónica las dimensiones histórica y dialéctica (Marchán-Fiz, 1982, pp. 244-45).

Un importante referente de la primera vía optimista que apuntaba a maximizar la cascada de la información y hacer elogio de la disolución del medio -de la arquitectura- en el mensaje -valorando la discursividad "barroca"-, sería Robert Venturi (1978). Venturi proponía un método de proyecto que actuaba como traductor y como filtro del mundo de referencias que podrían alimentar a cualquier arquitectura. El proyecto se redefinía así mediante citas, imitaciones, alusiones, recomposiciones, etc. y reconocía para ello dos canteras diferentes pero eventualmente complementarias: el mundo de la cultura popular y el mundo de la cultura histórica. Esta conducta caracterizada como propiamente posmoderna y liberada de toda pretensión fundacional o utópica de la arquitectura, señala que todo se inserta en el mundo de la información y que lo único posible, desde la perspectiva del proyecto, es la aportación a esos flujos de información. Venturi se proponía, según este programa inspirado en Macluhan, responder sintéticamente a la pregunta ¿qué leer y re-escribir (proyectar) respecto a lo popular y/o lo histórico? El programa era seguro. Se trataba de poseer una cultura figurativa, conocer y entablar relaciones sensoriales y emocionales con una especie de repertorio comunicable y seleccionar y aplicar un conjunto de referencias de dicho repertorio como forma de proyectar. Se trataba de reavivar ciertas imágenes reconociendo así en la función del proyectista la construcción de imágenes, y no de la realidad, todas estas imágenes transcritas de la arquitectura hecha o preexistente.

En Complejidad y contradicción en la arquitectura, Venturi trata de redefinir la vinculación de los hechos arquitectónicos con el pasado, en aras de vincular su lógica de la comunicación con una crítica implícita de la fundamentación de la arquitectura moderna sobre la abstracción y la autoreferencia. Venturi, proponía el simulacro que garantizase la comunicación simbólica eludiéndose las contradicciones de la supuesta identidad forma-función y la ética vitruviana de la materia. Si Mies decía "less is more", Venturi dirá "less is bore". El concepto de 'simulacro' que introducía también Moles en su Teoría de la información y percepción estética y el trasvase del 'grado de operatividad' tendría para Venturi si no un valor tecnológico sí un valor operativo-formativo fundamental con implicaciones directas sobre el criterio tradicional de verdad y significado de la arquitectura. Según la teoría de la información, se separan información y significación. La información es una cantidad con la que se puede medir el valor del mensaje, pues es tanto mayor cuando más inesperado, imprevisible y original. La carga informativa se reduce de forma inversa a la medida de lo imprevisible, lo improbable (A. Moles, 1976 pp.34-42). 
Opuesta a la postura de Venturi sería la de Hedjuk (1993, pp.9-16 y 19-32), por ejemplo, quien representaría esa segunda actitud hacia la textualidad poética, silenciosa y autónoma de la arquitectura que operaría con máxima reducción de elementos expresivos en aras de una escritura arquitectónica muy específica que revelaría una intención de restringir el problema de la arquitectura a su dimensión comunicativa y redefinir el proyecto como una práctica lingüística con la renuncia de su carácter anticipativo a la obra. Pero no como una prosa sino como la poesía que es el despojamiento de todo elemento suplementario del discurso hasta alcanzar un estado de abstracción o condición de disponibilidad y mutabilidad del sentido (Torres Nadal, 1993).

La tradición narrativa y permutacional del espacio arquitectónico, es oportuno recordar, comienza con Piranesi que en vez de prefiguraciones del espacio real construía efectos narrativos que proporcionaban sensaciones antes que la pura descripción o representación del espacio. Con la diferencia de que el proyecto arquitectónico se nutre ahora por otras narrativas distintas de los elementos de la arquitectura antigua que nutrían el discurso piranesiano.

La lógica comunicacional de Venturi se enfrentaba también a la lógica sintácticaestructuralista que pretendía una fundamentación del proyecto sobre lo esencial o las invariantes arquitectónicas que pueden atravesar la historia de manera inmutable (Fernández, 2007). Los referentes venturianos eran simplemente los socialmente conocidos y perceptualmente reconocidos de los cuales la arquitectura resultaría una evocación o una trascripción mientras que el estructuralismo buscaba la ideal condición fundacional y arquetípica de la arquitectura: una relación entre forma e institución-programa depurada o esencial, tipológica y abstracta en la obra de Luis Kahn que se opone a la historicidad contingente con su carácter suprahistórico; o la obra de Luís Barragán cuya referencia es la naturaleza o el paisaje. El "estado estructural" opera siempre en detrimento del "estado caogeno" y "entrópico" a favor del orden y en menoscabo de la información. Dicho de otro modo, la ganancia en orden (de los elementos) previsible de un estado estético, disminuye su innovación y su originalidad.

Resumidamente, la concepción arquitectónica en las últimas décadas transcurre entre la semántica y la sintáctica suponiendo en las estructuras sintácticas de las obras, el predominio del significante sobre el significado. De lleno en el campo de los objetos de génesis virtual, superada la estética de los objetos materiales por la 'estética generativa' (Bense,1969) -de las formas producidas por ordenador-, se relega a un plano secundario la relación entre sujeto -recipiente o percipiente- y objeto que pasará a ser sustituida por reglas: el código digital. La génesis incierta del objeto arquitectónico se basa en una teoría matemático-tecnológica de la transformación de un repertorio material en directivas de un programa y de las directivas a procedimientos donde interviene tanto el realizador como el computador -como generador casual- en un producto. La arquitectura está jugando así en dos terrenos: el de la construcción de la obra y el de la comunicación. En este último se puede convertir en un agente mediaticotransgresor que recaba del escándalo beneficios en términos de publicidad y de resonancia mediática mucho mayor, y eso es lo que cuenta más, aunque implique la ruptura con los deseos humanos. "Esa disensión se ha acrecentado enormemente 
hasta llegar a convertirse en irresoluble" (Perniola, p.76) y transformarse la arquitectura en un juego para iniciados del que -como observa Heinich (1998 $\left.{ }^{a}\right)$ están ausentes los inmediatamente interesados (figs.5 y 6 ).

\section{Experiencia del cuerpo y código digital}

De la nueva tecnología se desprende, sin embargo, una nueva forma de comunicación de todo con todos, una nueva solidaridad, un mito que Herman Hesse (1877-1962) hubiese podido engendrar sobre un hipotético lenguaje universal a través del cual podrían comunicarse e intercomunicarse todas las formas de la creación. Los límites entre disciplinas se van difuminando y las intersecciones entre arte, ciencias y tecnología están obligando a redefinir la idea de obra de arte, el espacio creativo y los papeles de autor y espectador. A través de los nuevos medios, todas las creaciones artísticas se difunden y se comunican sin límites y restricción, descienden al mundo cotidiano y práctico. Los medios de comunicación de masas propician así la globalización cultural como una unidad de la imagen o estilo del mundo. Así que la combinación de tecnología de la información y de la comunicación generan un lenguaje universal y transversal a todas las expresiones del arte, de la ciencia, de la vida cotidiana debido a que en su escritura, en el código digital, todo material científico o cultural puede verse reflejado.

Pero el código digital es un lenguaje abstracto, originado en la matemática y cuyos signos y operaciones no describen cualidades del sujeto. Por eso, su carácter indirecto y abstracto favorece una actitud de distanciamiento reflexivo (Arnheim, 1993). La utilización del software para proyectar implica que el arquitecto depende de un suministrador que le proporciona un medio de cuya estructura es ajeno. El medio para proyectar es un metalenguaje a cuya estructura no tiene acceso. La computación basada en el propio proceso neuronal, aplicada a un proceso arquitectónico creativo es un proceso completamente articulado mediante la tecnología. El conflicto se produce en el momento que el dibujo arquitectónico es proyecto de algo que no existe y no representa ningún objeto preexistente. Pero, las representaciones del ordenador sólo operan con modelos; ofrecen la posibilidad de trabajar directamente en modelos tridimensionales; generan, además, infinitas representaciones del modelo en sí; transforman totalmente la actitud proyectual en relación con modelos preestablecidos (Mantzou, 2008). Es evidente, como decía Mc Luchan (1963) que los medios nunca son neutros y configuran de modo eminente nuestra relación con el mundo. Si el arte abstracto -pintura, escultura, arquitectura- fue la invención de un código óptico, el código digital, es un código completamente articulado que coincide con la definición de un espacio óptico puro codificado. Según Deleuze (2004, p.124), el espacio digital sería la máxima subordinación de la mano al ojo, la mano que se ha fundido. Sólo subsiste un dedo para operar la elección binaria visual. La mano es reducida al dedo que apoya sobre el teclado. Es decir, es la mano informática. Es el dedo sin mano. El lenguaje analógico, sin embargo, es casi lo inverso; expresa directamente relaciones analógicas de dependencia. Si el lenguaje digital está totalmente articulado y convencional, el lenguaje analógico es no-articulado. Está hecho de cosas no lingüísticas. Está hecho de movimiento, de expresión de las emociones. Está hecho 
de datos muy heterogéneos. Se trata de un lenguaje que establece relaciones entre el emisor y el receptor. La estructura de ese lenguaje expresa directamente funciones de dependencia y su diferencia de un lenguaje absolutamente codificado, como es el lenguaje digital, consiste en que éste es esencialmente hecho para designar estados de cosas. ((Deleuse, 2004, p.138).

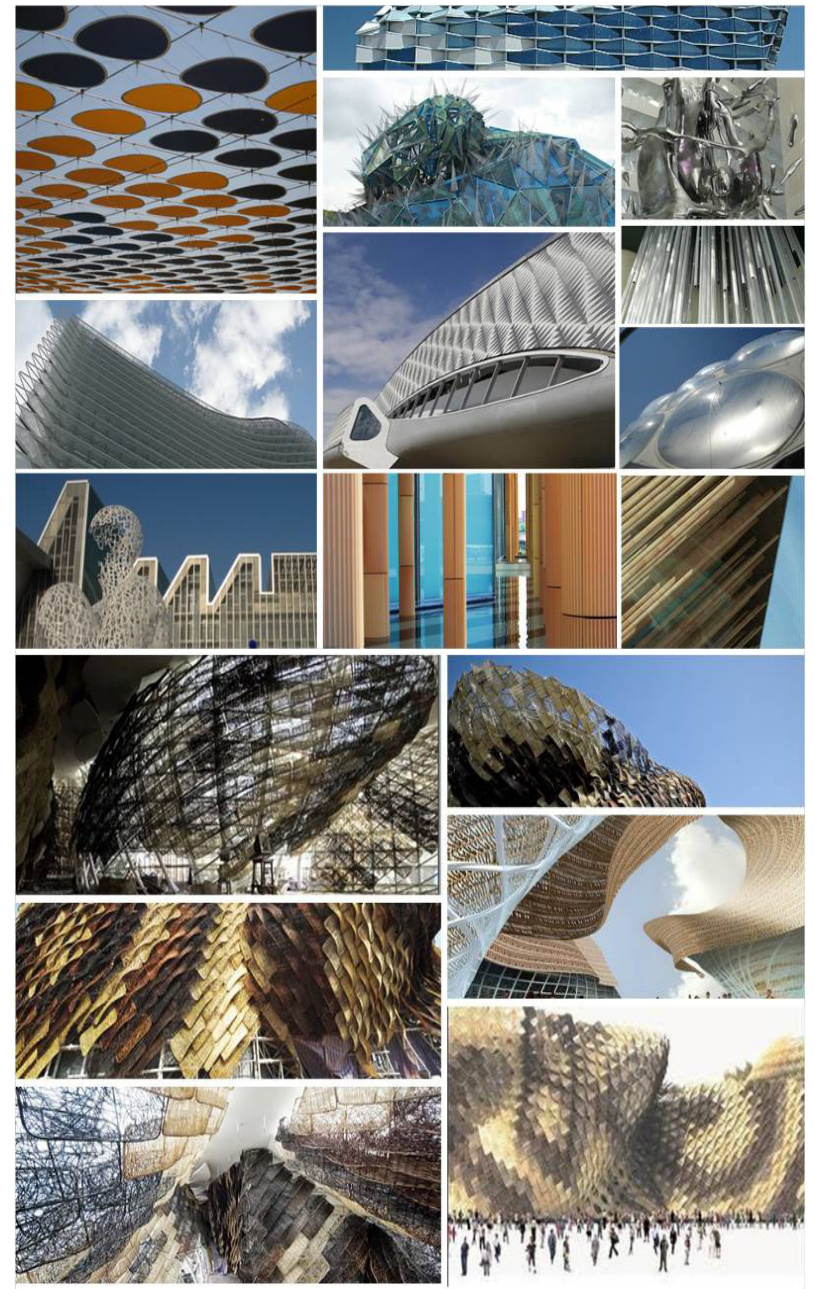

Fig.5. Arriba: materiales y texturas encontrados en las instalaciones de la Expo de Zaragoza. Todos denotan singularidad y responden a la solicitación más importante a resolver que es cómo intensificar la percepción sensorial y la seducción, asociando siempre tecnología y comunicación. Abajo: Pabellón de España en la Expo de Shanghai de EMBT: Miralles-Tagliabue, 2010. Su singular diseño está basado en una estructura metálica cubierta por paneles de mimbre, de diferentes tonalidades. Este insólito material para este tipo de estructuras, recuerda construcciones primitivas y se ha elegido para simbolizar el nexo de unión entre labores artesanales chinas y españolas; tal vez también para simbolizar la sostenibilidad con el uso de materiales naturales; pero tan sólo simbolizar porque ejecutar tan singulares piezas de mimbre no debe resultar nada económico; sin embargo sí garantiza una imagen toralmente singular. 
La inmaterialidad de los procesos digitales, su falta de tactilidad, la ausencia de escala y la manipulación sin fin de los modelos distan mucho de los procesos analógicos tradicionales del proyecto arquitectónico. En los dibujos y las maquetas las huellas de las manos son presentes. A falta de involucrarse la mano y la pérdida de la apasionada aportación del gesto, de los trazos de la mano en el papel y en los volúmenes plasmados, el ojo sigue adquiriendo una soberanía total. Dada la frialdad del código, que reserva para la mano la condición mediadora del interface, la arquitectura destinada al tacto y a la percepción cinestésica tiene serias dificultades en plasmarse. La mano reemplazada sobre el papel es el principio de un cambio aún más trascedente que es el cuerpo reemplazado sobre la tierra. Los interfaces permiten que se pierda la relación corpórea entre el autor y el modelo. La mano y los modelos analógicos son sustituidos por los interfaces y los modelos digitales. Pero ni la mano, ni el ojo, ni el cerebro hablan el lenguaje del código digital sino que funcionan gracias a los traductores tecnológicos. Así el acceso al lenguaje arquitectónico queda irreversiblemente perdido y suplantado por la inmaterialidad y la universalidad del código digital

Una de las características del código digital es el hecho de ser totalmente manipulable, flexible y maleable; permite modificaciones infinitas, ofrece una libertad absoluta y una tremenda dificultad de delimitar los procesos. Frente al dibujo tradicional que registra de un modo fijado el grafito sobre el papel, el boceto digital y tridimensional se manipula de múltiples maneras, ofrece la posibilidad de manipular cada punto por separado aniquilando así los conceptos de orden, composición y jerarquía con una enorme repercusión sobre formas arquitectónicas de una nueva generación. Frente a la lógica geométrica que trabaja con figuras, es decir líneas, planos volúmenes organizados en el espacio, se trata de una lógica algebraica. En las combinaciones algebraicas los elementos independientes se combinan de forma aditiva formando totalidades indeterminadas, abiertas y no jerarquizadas, sin restricciones, sin procesos preestablecidos, lo que supone una revolución del modo de concebir y realizar el proyecto arquitectónico. Este cambio afecta profundamente el lenguaje arquitectónico y como consecuencia la relación cognoscitiva entre la arquitectura y el ser humano. Los nuevos medios efectivamente producen imágenes que no expresan las cualidades táctil y plástica del espacio arquitectónico, imágenes en las cuales los receptores no reconocen experiencias humanas esenciales. El universo interno del hombre formado por hitos, coordenadas, jerarquías y sobre todo con unos límites propios, es imposible que constituya el punto de partida de la organización del espacio digital. El cuerpo se liga estrechamente y depende fuertemente de la arquitectura. El movimiento corporal está sometido a las mismas leyes físicas que rigen las formas construidas y esas formas poseen la capacidad de contenerlo, limitarlo y dirigirlo físicamente. La arquitectura, como se ha dicho, es la construcción de lugares, es, ante todo, "la acción de extender el mundo interior de los seres humanos al mundo exterior creando formas aprehensibles capaces de ser experimentadas y habitadas" (Bloomer, K. C., Moore, Ch. W. 1982). La compatibilidad del espacio vital del hombre y el código digital queda en entredicho. 


\section{Arquitectura y cuerpo ampliado por la tecnología}

Si es verdad que la realidad construida como un medio visual y el papel de la arquitectura como un medio -y no como fin- de comunicación de masas, empieza en la Ilustración como una voluntad política-estratégica de establecer nuevos modelos espaciales de vocación universalista aniquilando memoria, lugar e identidad, la potencia psicotrópica de la imagen digital lleva al síndrome de la amnesia actual que borra los lugares pues, la memoria digital tiene la facultad de producir imágenes de edificios y ciudades que no estén en ninguna parte. Se puede hablar de generaciones de la visión e incluso de una herencia visual entre una generación y la siguiente pero el surgimiento de esa nueva "logística de la percepción", y sus vectores de deslocalización, y desrealización, no es sólo una renovación de la óptica geométrica que se inauguraba en la Ilustración sino un eugenismo de la mirada, un aborto originario de la diversidad de las imágenes mentales, de la multitud de entesimágenes que ya no iban a nacer, que ya no verían el día en parte alguna" (Virilio, 1998, pp. 21-23).

Cuando la sociedad industrial transita hacia la sociedad de la información y del consumo, los valores simbólicos obtenidos mediante la información, más que los valores inherentes a las cosas, son los que fomentan el consumo. Eso se hizo patente en la arquitectura a partir de finales de la década de 1980. Esta arquitectura adornaba el espacio homogéneo resultante de la industrialización (estructura modular, con un esqueleto de hormigón y acero, con piel separada de la estructura, con cubiertas planas...estilo internacional) con símbolos que promovían el consumo. "Casas con estructuras modernas estándar y homogéneas tenían fachadas concebidas como símbolos para un hogar satisfecho". En el espacio de la ciudad contemporánea, a pesar de la homogeneidad, flota un infinito número de símbolos que pueden asumir cualquier significado imaginable y el hecho de poder cambiar de significado independientemente de la estructura, proporciona la impresión de haber conseguido un espacio muy libre. Se podría llamar el "mundo de las formas libres" al espacio cartesiano de la codicia liberado por el flujo de la información; un espacio que garantiza las dinámicas de la sociedad de consumo y las respalda. El lenguaje de la arquitectura contemporánea no impone ninguna restricción como hacía el lenguaje del estilo internacional. Como todo símbolo que estimula el deseo de consumo es libre y cada uno puede escoger y darle la forma que le guste (Ito, 2006, pp.1114). Podríamos así decir, que estamos avanzando, hacia un sentido refractario a los sistemas del lenguaje de la comunicación donde se privilegia el símbolo -el icono- y se va abandonando la tradición del signo.

En los espacios emergentes no se reconocen los códigos de los antiguos espacios de la comunicación social -las calles, avenidas y plazas públicas-; son espacios sorprendentes, extrañantes que se pueden argumentar tanto con las metáforas de los fractales, como con las teorías del caos y la disiminación pero también con analogías e incluso con la mímesis directa de formas naturales como hace Toyo Ito. Ante la justificación de que telecomunicación y teleproducción no requieren ciudades bien hechas, como diría Rem Koolhaas, y la desintegración de la ciudad física frente al 'simulacro' de los espacios sociales en las redes, un infinito número de símbolos flota 
en el espacio de la ciudad. Estas imágenes fragmentarias son las que somos capaces de ver a través de las pantallas y las cámaras, estas auténticas "máquinas de la visión" que son las que ven y perciben por nosotros y en lugar de nosotros. El medio virtual es ya el medio natural de nuestra existencia. En palabras del oriental Tsutomu Toda, "la interface forma casi parte del cuerpo. Si el cuerpo pudiera prever la velocidad y el comportamiento del ordenador y de la pantalla como su dispositivo de salida, algunos de los elementos sensibles del ordenador se transformarían en sus miembros. La pantalla parece una superficie de agua y trabajar con el ordenador produce la sensación de meter los pies en el agua. No está fuera, pero tampoco está dentro de uno. Sin duda esta extraña realidad redefinirá el ámbito del yo" (Ito, 2006. pp. 21).

$\mathrm{Si}$ al espacio homogéneo y euclidiano del movimiento moderno, se le podía dar forma material -como hizo Mies van der Rohe utilizando el acero y el vidrio o Le Corbusier utilizando el hormigón, éste, se podría decir todavía que, era el espacio requerido por el "cuerpo del movimiento mecanicista moderno", cuerpo identificado con el cuerpo de la experiencia vivida en contraposición al "cuerpo del movimiento electrónico moderno". El cuerpo ampliado por la comunicación en la sociedad interconectada difiere significativamente de aquello que había sido el objetivo en los inicios del movimiento moderno. El espacio característico de los principios del movimiento moderno es una malla cuadriculada que sigue la geometría euclidiana, un espacio transparente de extensión infinita, pero sí un espacio visible que se podría dar forma como hicieron Mies y Le Corbusier. "El cuerpo del movimiento electrónico moderno" exige, sin embargo, un espacio todavía menos localizado que aquel que creó el movimiento mecanicista moderno, incluso más transparente y homogéneo; requiere una ciudad diferente e invisible. De hecho vivimos, en una ciudad que se adapta al cuerpo vivido biológico y a la vez en otra donde se encuentra en casa el cuerpo ampliado producido por la red electrónica. ¿Cómo puede el arquitecto dar una imagen visible a esta otra ciudad invisible? ¿y cómo se puede registrar esta imagen en la ciudad de la experiencia vivida? se pregunta Toyo Ito. El espacio requerido por ambos cuerpos, tanto el "cuerpo del movimiento mecanicista moderno", el "cuerpo de experiencia vivida" como el "otro cuerpo" de la conciencia ampliada creado mediante la nueva tecnología, se llena de transparencia y homogeneidad pero en el primero, entre lo externo y lo interno se establecía comunicación a través de un límite. Pero debido a la tecnología ahora se están introduciendo cambios a este límite. La visualización de la pantalla es información del exterior, pero también una proyección del interior. En lo que se refiere al cuerpo, el límite entre el exterior y el interior se va desdibujando, y si se intenta definir este límite exactamente, se correría el riesgo de invadir el límite del yo. Ser conscientes de unos mismos, podría peligrar y desvanecerse (Ito, 2006. pp. 19-23).

El cuerpo ampliado mediante la tecnología electrónica sugiere a Toyo Ito la idea de una "forma fluida" del espacio donde se experimenta la misma sensación de "flotación" del cuerpo que en el medio fluido electrónico. Imagina Toyo Ito, edificios y ciudades fundidos con la naturaleza, "una arquitectura blanda de límites difusos" que puede reaccionar ante el entorno natural; una arquitectura que siendo continuación del Movimiento Moderno está condicionada por un entorno artificial producido por las nuevas tecnologías (fig. 6). Eso es así porque no cabe el retorno 
a una vida exclusivamente dependiente del entorno natural pero no por eso, sugiere Toyo Ito, deberíamos perseguir una arquitectura apartada de la naturaleza y que se encierre en sí misma. Con el entorno artificial como base, el objetivo sería adoptar un límite sensible para responder a los elementos de la naturaleza: luz, agua, viento, etc; responder sensiblemente a la naturaleza; un límite que funcione a modo de sensor, a semejanza de la piel humana y tan sensible como ésta. Debe ser una arquitectura que incorpore una relación interactiva entre el entorno artificial y el natural, garantizando un hogar agradable para el nuevo cuerpo (Ito, 2006. pp. 28).
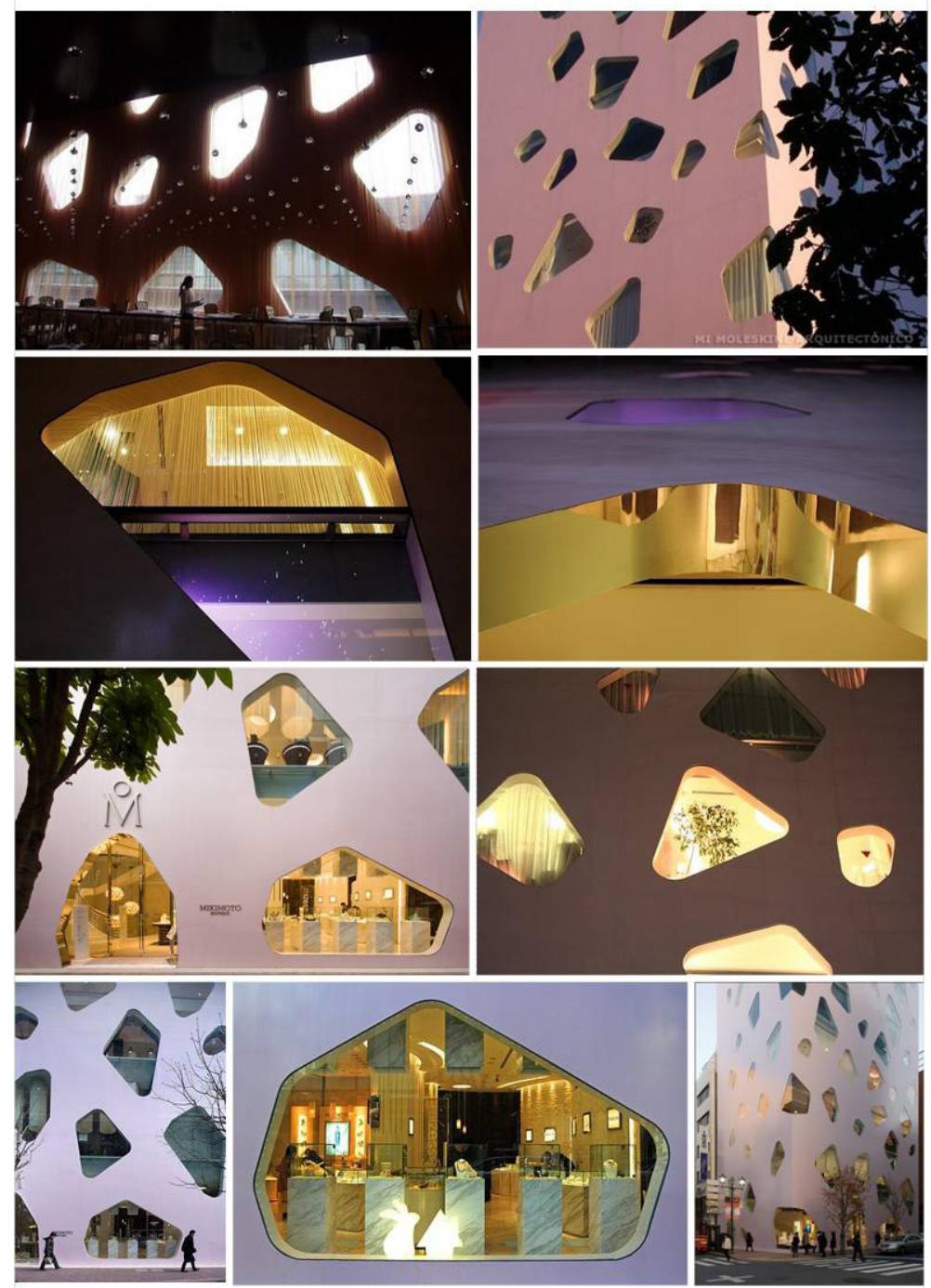

Fig.6. Edificio Mikimoto en Tokio, de Toyo Ito, 2004. Arquitectura de límite sensible, metáfora de cuerpo vivo, poroso que transpire e intercambia energía con el entorno y los seres humanos. 
El ciberespacio habría de ser además, según Toyo Ito, un espacio que implementase las acciones humanas en el espacio arquitectónico suprimiendo los límites basados en las 'funciones'; un espacio que haga que aparezcan lugares diferenciados a nivel arquitectónico por las acciones de diversas corrientes debidas tanto a factores naturales como a individuos o a grupos de personas o a una gran concentración de información. Sería ese un espacio donde "las personas recobrarían la sensación de estar realmente vivas". Un espacio de verdadera interacción donde la tecnología se transformase en potenciador de la percepción y de las relaciones humanas. Telecomunicación y teleproducción no necesariamente habrían de ser una limitación de las posibilidades de configuración del espacio físico sino que podrían generar las condiciones necesarias para un entorno humano más sostenible y mejor habitable.

Tal vez, sea este un filón para la investigación en arquitectura, para encontrar las vías de optimización de la influencia de las nuevas tecnologías de la información y la comunicación en el diseño de espacios más humanos reconvirtiendo los factores que operan hoy negativamente sobre la calidad ambiental en precursores de un nuevo espacio para la realización individual y la integración social. Eso implicaría repensar "la arquitectura del cuerpo" frente a "la arquitectura del ojo" y su obstinada persecución -desde el barroco- a producir efectos para el aprovechamiento estético sin vinculación a la propia vida, a modo de obtener el mayor impacto estético mediante el menor uso de material significativo y encontrando en las nuevas tecnologías de la producción y la reproducción icónica -ya son las mismas- su mejor aliado en el trabajo sistemático de la conversión de la realidad en ficción.

$\mathrm{Si}$ es verdad, el producto arquitectónico adopta las características de la estructura propia para la difusión, la comercialización y el consumo de las ideas y los productos en general, la estructura de una poderosa imaginería para la virtualidad del espectáculo, podríamos explorar la "politecnología actual" -lo que puede considerarse la informática en combinación con las telecomunicaciones y otras tecnologías- como generador de nuevos usos, formas interactivas entre grupos, campos y ramas del conocimiento pero también nuevos ámbitos de acción totalmente inexplorados. Sin duda, las ideas se estimulan a través de su migración entre los diferentes medios pero en este contexto neotécnico de la infinita producción de imágenes -anunciado como "la muerte del aura" por Benjamin y "el arte como mercancía" por Adorno-, la ideación arquitectónica asistida por ordenador, resulta paradójico, esconde detrás de la singularidad y la innovación continua, los viejos clichés, imágenes llenas de contenido mitológico y comercial, los camuflajes, las pieles y las apariencias segregadas de un neobarroco siempre en esta tensión entre la disciplina arquitectónica y las técnicas comunicativas. La arquitectura asume así su posición en el mundo del espectáculo cuyo significado se asienta en "una relación social entre individuos, mediada por las imágenes" (Debord, 1990, p. 87). 


\section{Referencias}

Aalto, A. (2000). Arte y técnica. En Schildt, Göran (Ed.), Alvar Aalto. De palabra y por escrito (pp.51-56). El Escorial: El Croquis Editorial.

Adorno, Th. (2005). Teoría estética. Madrid: Ediciones Akal.

Adorno, Th. (2005). Escritos sociológicos y (2009) Escritos sociológicos II. Volumen 1. Madrid: Ediciones Akal.

Arnheim, R.(1986). El pensamiento visual. Barcelona: Paidós.

Arnheim, R. (1993). Consideraciones sobre la educación artística. Barcelona Paidos Estética.

Bachelard, G. (1975). La poética del espacio. Madrid: Fondo de Cultura Económica.

Benjamín, W. (1973). La obra de arte en la época de la reproductibilidad técnica. Discursos interrumpidos. Madrid: Taurus.

Bergson, H. (1996). Matière et Mémoire. Essai sur la relation du corps a l'esprit. París: Presses Universitairs de France.

Bense, M. (1973). Introducción a la estética teórico-informacional. Madrid: Alberto Corazón.

Bloomer, Kent C., Moore, Charles W. (1982). Cuerpo, memoria y arquitectura: introducción al diseño arquitectónico. Madrid: H. Blume.

Bourdieu, P. (2000). Una interpretación de la teoría de la religión según Max Weber. Intelectuales, política y poder. Buenos Aires: Eudeba.

Castillo Santana, R. (2007). Influencia de la estética en los objetos virtuales. Tesis doctoral dirigida por Francisco Asís Caja López, Universidad de Barcelona, Dto.de Historia de la Filosofía, Estética y Filosofía de la Cultura.

Costa, J. Abraham Moles (2007). Publicidade e deseño: o novo reto da comunicación. Santiago de Compostela: Lea.

Debord, G. (1990). Comentario a la sociedad del espectáculo. Barcelona: Anagrama.

Deleuze, G. Guattari, F. (1994). Mil mesetas. Capitalismo y esquizofrenia. Barcelona: Ed. Pre-textos.

Deleuze, G. (2007). Pintura. El concepto de diagrama. B. Aires: Ed. Cactus. Derrida, J. (1989). L'ecriture et la différence. Barcelona: Ed. Anthropos. Echeverría, J. (1994). Telépolis. Barcelona: Destino.

Echeverría, J. (1995). Cosmopolitas domésticos. Barcelona: Anagrama. Echeverría, J. (1999). Los señores del aire: Telépolis y el tercer entorno. Barcelona: Destino.

Eco, U. (1997). Tratado de semiótica. Barcelona: Ed. Lumen. Eliade, M. (1972). El mito del eterno retorno. Madrid: Alianza Ed. Fernández, R. (2007). Lógicas del Proyecto. Buenos Aires: Editorial Concentra. Fiedler, K. (1990). El origen de la actividad artística. Escritos sobre arte. Madrid: Visor, La Balsa de la Medusa.

Franke, H.W. (1985). Computer graphics, computer art. Berlin-Heidelberg: Spinger-Verlag.

Gadamer, H.G. (1993). Están enmudeciendo los poetas. Poema y diálogo. Barcelona: Ed. Gedisa. 
Gadamer, H.G. (1998). Estética y hermenéutica. Madrid: Tecnos. Harvey, D. (1998). La condición de la posmodernidad. Investigación sobre los orígenes del cambio cultural. Buenos Aires: Amorrurtu.

Hedjuk, J. (1993). Victimas. Murcia: Ed. COAAT-Yerba.

Heidegger, M. (1994). La pregunta por la técnica. Conferencias y artículos. Barcelona: Ed. del Serbal.

Heinich, N. $\left(1998^{\mathrm{a}}\right)$. Le triple jeu de l'art contemporain. París: Minuit. Hugo, V. Nuestra señora de París, libro V, capítulo 2: Esto matará aquello. Ito, T. (2006). Arquitectura de límites difusos. Barcelona: Gustavo Gili.

Jameson, F. (1996). Teoría de la posmodernidad. Madrid: Ed. Trotta.

Lyotard, J. F. (1994). La condición postmoderna: Informe sobre el saber. Madrid: Ed. Cátedra.

Mantzou, P. (2008). Proyectar en la era del código digital. Actas XII Congreso Internacional de Expresión Gráfica Arquitectónica, Madrid.

Marchan Fiz, S. La estética científica de Max Bense. M. Bense, M. (1973) Introducción a la Estética teórico-informacioanal. Madrid: A. Corazón.

Marchán Fiz, S. (1986.3). Del arte objetual del arte del concepto. Madrid: Akal.

Marchán Fiz, S. (1986.3). La computadora digital como medio creativo. Del arte objetual del arte del concepto. Madrid: Akal.

Marchán Fiz, S. (1987). La estética en la cultura moderna. Madrid: Alianza Ed. McLuhan, M. (1993). La galaxia Gutemberg. Barcelona: Círculo de Lectores.

McLuhan, M. Fiore, Q. (2000). The Medium is the Massage. New York: Random House.

McLuhan, M. (1994). Comprender los medios de comunicación. Las extensiones del ser humano. Barcelona: Paidós.

McLuhan, M. (1998). Escritos esenciales. Barcelona: Paidós.

Moles, A. (1976). Teoría de de la información y percepción estética. Gijón: Ed. Jucar.

Montaner, J. M. (1999). Arquitectura y crítica. Barcelona: Gustavo Gili.

Pallasmaa, J. (2008). Los ojos de la piel. La arquitectura y los sentidos. Barcelona: Gustavo Gili.

Perniola, M. (2002). El arte y su sombra. Madrid: Cátedra.

Ricoeur, P. (1995). Sí mismo como otro. Madrid: Siglo XXI.

Sartre, J.-P. (1970). Crítica de la razón dialéctica. Buenos Aires: Losada.

Sostang, S. (1981). Sobre la fotografía. Barcelona: Edhasa.

Torres Nadal, M. (1993). Introducción de J. Hedjuk. Victimas. Murcia: Ed. COAAT-Yerba.

Vatimo, G. (2003). El sujeto y la mascara: Nietzsche y el problema de la liberación. Barcelona: Península,

Venturi, R. (1978). Complejidad y contradicción en la arquitectura. Barcelona: Gustavo Gili, Col. Arquitectura y crítica.

Virilio, P. (1998). La máquina de la visión. Madrid: Cátedra, Signo e imagen.

Weber, M. (1970). La ética protestante y el espiritu del capitalismo. Barcelona: Ed. Península. 